\title{
Characterisation of Moisture-Dependent Cohesive Zone Properties for Adhesively Bonded Joints
}

\author{
Katnam KB ${ }^{a}$, Sargent JP ${ }^{b}$, Crocombe $A D^{a *}$, Khoramishad $H^{a}$ and Ashcroft IA ${ }^{c}$ \\ a Mechanical, Medical and Aerospace Engineering, University of Surrey, Guildford, \\ GU2 7XH, United Kingdom
}

${ }^{\mathrm{b}}$ BAE Systems, Advanced Technology Centre, FPC 267, PO Box 5, Filton, Bristol, BS34 7QW, United Kingdom

${ }^{\mathrm{c}}$ The Wolfson School of Mechanical and Manufacturing Engineering, Loughborough University, Leicestershire, LE11 3TU, United Kingdom

\section{ABSTRACT}

Structural adhesives are being widely used in the aerospace and automobile industries. However, in many applications, aggressive environments damage the adhesive systems and degrade the structural performance of bonded members. Cohesive zone models are often employed in the numerical analysis of adhesively bonded structural joints. To accurately model these bonded joints, the characterisation of the cohesive zone properties for different environmental conditions is important. In this regard, an experimental-numerical approach was developed to characterise the environment-dependent cohesive zone properties based on a miniature cantilever peel test. As moisture is a commonly encountered aggressive environment, the current methodology was implemented to characterise the moisture-dependent cohesive zone properties for Al 2024-T3 and FM73 system.

Keywords: Structural adhesives, cohesive zone modelling, cantilever peel test, FM73 and non-linear analysis. 


\section{INTRODUCTION}

Advances in material science and polymer technology have introduced new composite materials and better structural adhesives. Advanced structural adhesives are used widely in automobile and aerospace applications [1-4]. Adhesive bonding has gained importance in composite and metallic structures because of its advantages over the conventional methods of joining materials [5]. However, as bonded joints will be exposed to complex mechanical loading and aggressive environments, reliable design rules can only be proposed with better understanding of the failure mechanisms involved under service conditions.

Adhesively bonded structural members are, in many situations, exposed to hostile environmental conditions during their service life. Water, being one such aggressive environment, may enter into adhesive joints and weaken the adhesive and the bond strength. The diffusion of water in bonded metallic structures can be through (a) the adhesive, (b) the adhesive-adherend interface and (c) cracks or discontinuities in the adhesive [6]. When exposed to aggressive environments, most structural adhesives typically lose strength during initial period and the rate of degradation levels off after certain exposure time [7]. However, the environmental degradation of adhesively bonded systems is complex and strongly dependent on the system being bonded. In this regard, it is necessary to conduct carefully designed experiments on bonded joints that are subjected to different mechanical loadings and humid environments to investigate the failure mechanisms. Further, developing numerical models to accurately predict the experimentally observed failure behaviour is vital from a design viewpoint.

To develop predictive models that address strength and durability of bonded joints, numerical approaches based on fracture and damage mechanics have frequently been employed [8-10]. An important issue when considering failure in these bonded joints is the fact that structural adhesives display some ductility before failure and do not exhibit perfect brittle behaviour [11]. In fact, damage initiates ahead of the physical crack tip through shear-yielding, crazing, or micro void formation. In this 
regard, cohesive zone models, which were originally introduced by Barenblatt [12], Dugdale [13] and Hillerborg et al. [14], have been used to model the fracture behaviour in adhesively bonded joints. The cohesive zone approach is particularly useful when the crack initiation and propagation phases in the bondline need to be incorporated into a single analysis. A traction-separation response is used to model the damage initiation and evolution in the fracture process zone, and a parameterized traction-separation shape is generally employed in the analysis [15]. The parameters that define the traction-separation response mainly are the cohesive fracture energy and the critical traction of the adhesive in each fracture mode [1617]. Some experiments that are commonly used to determine these adhesive parameters are the double cantilever beam test, the end-notched flexure test, the mixed mode flexure test and the notched coating adhesion test [18]. Once the cohesive parameters for each fracture mode are determined by simple fracture tests, the model can make accurate predictions for the entire fracture process of any joint geometry and under any applied loads.

As the moisture diffusion in the bondline weakens the bond strength through reversible (i.e. adhesive plasticization) and irreversible phenomena (i.e. crack or disbond formation) the cohesive properties will be degraded based on the moisture concentrations [19]. In adhesively bonded joints, moisture enters the joint at the exposed adhesive surfaces and diffuses into the core. A three-dimensional variation of moisture concentration exists in an unsaturated adhesively bonded joint, i.e. a saturated state near the exposed adhesive surfaces and an unsaturated or a dry state at the core of the adhesive layers. As the moisture concentration adversely influences the cohesive properties, moisture-dependent cohesive properties are required to accurately predict the failure behaviour of a saturated or unsaturated adhesively bonded joint using the cohesive zone approach.

In this paper, an experimental-numerical approach is presented to determine the moisture-dependent cohesive properties. An adhesively bonded aluminium laminate (2024-T3 and FM73) was used. The laminate was immersed in de-ionised water at $50^{\circ} \mathrm{C}$. Using miniature cantilever peel tests and cohesive-zone finite element 
modelling, the cohesive properties were determined for different moisture concentrations. The experimental test details and numerical strategy employed are presented. This work focuses on the cohesive parameters of the bulk adhesive because the failure mode of the adhesive system being considered was found to be cohesive under both wet and dry conditions. The same approach can also be applied even if the mode of failure is interfacial. In this situation the critical energies and tractions relate to the degraded interface rather than the bulk adhesive.

\section{EXPERIMENTAL WORK}

Various experimental test procedures are employed to determine the fracture properties of structural adhesive systems [20]. Specific test configurations have commonly been used to determine the adhesive properties for different fracture modes. Generally, the double cantilever beam and the end-notched flexure tests can give the adhesive fracture energies in mode-I and mode-II, respectively.

\subsection{Cantilever Peel Test}

The cantilever peel test [21] discussed in this paper provides an alternative means of measuring the peel-dominated fracture data with relative ease. In the cantilever peel test, the adherends are pulled from each other at a constant rate and the peel force that is applied to fracture the adhesive bond is measured. The adhesive fracture energy and the adherend plastic bending energy both contribute to the measured peel strength. The adhesive fracture energy can be determined from the experimentally measured peel strength using numerical methods by incorporating the adherend plasticity.

The peel force depends on many factors, i.e. the type of structural adhesive, the environmental conditioning, the type of adherend, the peel rate, the angle between the adherends, the surface preparation etc. The peel force can be significantly affected by the process of cavitation and fibrillation of the adhesive [22]. Further, as moisture weakens the adhesive properties and also initiates void formations, it 
influences the peel force substantially. In the current research work, a miniature cantilever peel test was employed to determine the moisture-dependent cohesive zone properties of an adhesive system in mode-l dominated fracture.

\subsection{Adhesive System}

An adhesively bonded aluminium laminate was used in the experimental work. The aluminium alloy (2024-T3) laminae were bonded using Cytec FM73 to manufacture the laminate. The aluminium surfaces were etched with chromic acid and anodised with phosphoric acid and then BR127 primer was applied to provide environmental resistance and durability. Specimens cut from the adhesively bonded laminate were exposed to de-ionised water at $50^{\circ} \mathrm{C}$ for a year. The geometry and dimensional details are given in Fig. 1. Moisture diffuses from all six faces. However, diffusion for only four faces is shown in Fig.1. Moreover, as the length of the specimen was $>200$ $\mathrm{mm}$, diffusion in the z-direction governs the moisture concentrations in the middle of the specimen. The laminate had six aluminium alloy 2024-T3 laminae, each of 1.3 $\mathrm{mm}$ thickness. The adhesive FM73 bondline between any two aluminium laminae was $0.1 \mathrm{~mm}$ thick. The width of the laminate specimen was $15 \mathrm{~mm}$.

Moisture transport in the structural adhesive FM73 is governed by Fickian diffusion [23]. An initial one-dimensional diffusion analysis showed that the width of the laminate was large enough for the adhesive FM73 to have a significant non-uniform moisture distribution after a year of exposure to de-ionised water. After exposure the laminate was cut along the length ( $x y$-plane) into $1.0 \mathrm{~mm}$ thick slices as shown in Fig. 2 (with a $0.5 \mathrm{~mm}$ thick cutting blade). The resulting 5 slices from the outer edge to the middle of the laminate are denoted as $A, B, C, D$ and $E$, respectively. As the width of each slice was $1.0 \mathrm{~mm}$, the variation of the moisture concentration over this length was modest and the average value, obtained from a diffusion analysis, was used to characterise each slice. In an unsaturated condition, the normalised moisture concentration will be 1.0 at the outer edge of the laminate (Slice A) and decrease towards the middle (Slice E). 


\subsection{Dry and Wet Peel Tests}

Initially, a dry laminate was cut and $1.0 \mathrm{~mm}$ thick slices were produced. The specimens were tested in order to obtain the variation of the peel force with the crack length (called the $P$ - $a$ curve from here onwards) for the dry adhesive condition. As there were five adhesive bondlines in the specimen, peel tests were conducted for each bondline by applying the peel load to each aluminium lamina successively. The peel load was applied through a pin running through a small ( $0.5 \mathrm{~mm}$ diameter) hole drilled in the aluminium lamina. The bottom lamina was clamped in grips. An initial crack length of $2.0 \mathrm{~mm}$ was inserted using a razor blade in the bondline, and the $P$-a responses were measured for all the bondlines. The experimental $P$-a curves for all the five bondlines were very close to each other as can be seen later in Section 4. It indicated that the same bond quality was achieved in all the bondlines in the laminate. The failure obtained from these dry peel tests was cohesive in nature.

Following the dry specimen testing the laminated specimen exposed for 1 year were cut similarly into 5 slices. Moreover, as the length of the laminate was $>200 \mathrm{~mm}$, each slice was cut into three specimen (e.g., Slice A of $>200 \mathrm{~mm}$ was cut into three specimen - Slice $A 1, A 2$ and $A 3$ of $>65 \mathrm{~mm}$ each). Peel tests were conducted on each specimen obtained from Slice A, B, C, D and E. A total of 15 tests ( 3 specimen $\times 5$ slices) were performed. As the dry peel tests showed little variation in bond quality for the different bondlines, only the top adhesive bondline was considered for all the wet peel tests. An initial crack length of $2.0 \mathrm{~mm}$ was again inserted in the top adhesive bondline, and the $P$ - $a$ curves were obtained for all the tests. The results presented and discussed in Section 4.

\section{NUMERICAL ANALYSIS}

\subsection{Cohesive Zone Models}

Most of the engineering materials, including structural adhesives, do not exhibit the perfect brittle fracture behaviour in the Griffith sense. A small fracture process zone 
ahead of the crack trip exists where material yielding, micro-cracking, void formation is generally observed. To incorporate these complex phenomena acting in the fracture process zone, cohesive zone models are frequently used in numerical analysis. The process zone in adhesively bonded metal laminate is schematically shown in Fig. 3(a). As the cohesive forces vary in the process zone, several tractionseparation response laws have been employed to model fracture in these materials [24]. In this work, a bilinear traction-separation response was used to model the bondline, see Fig. $3(\mathrm{~b})$. The cohesive strength $\left(\sigma_{c}\right)$ and the fracture energy $\left(\Gamma_{c}\right)$ are the two most important parameters to model the traction-separation response [16].

\subsection{Adhesive Stress State}

In the cantilever peel test, the adherends are pulled away from each other at a constant rate and the peel force is measured. The peel force is applied to the top adherend. The stress state that exists in the bondline due to the bending moment at the peel front is shown in Fig. 4. Peel ( $y$-direction) and shear stresses ( $x$-direction) are generated because of the bending of the adherend. Moreover, as the adherend and the adhesive contract by different amounts in the $z$-direction, shear stresses are induced in the $z$-direction. These shear stresses are maximum at the two adhesive edges and vanish in the middle of the adhesive bondline. This is shown in Fig. 4. For simplicity, only the peel and shear stresses acting on the $x-z$ face are shown. The stress states near the edges and at the middle are denoted by $\left(\sigma_{y}^{o}, \tau_{x y}^{o}, \tau_{y z}^{o}\right)$ and $\left(\sigma_{y}^{*}, \tau_{x y}^{*}, \tau_{y z}^{*}=o\right)$. This may cause mode-mixity in the fracture process. A finite element analysis was performed to calculate these stress components. It was however found that the peel stresses dominate the fracture process, though the mode-II $\left(\tau_{x y}\right)$ and mode-III $\left(\tau_{y z}\right)$ shear stresses existed. The results are presented in Section 4.

\subsection{Moisture Diffusion}

As the miniature peel tests were conducted on specimens cut from a laminate that was immersed in de-ionised water for 360 days, the moisture concentrations in the 
bondline were analysed for the same time period using the Fickian diffusion solution. The one-dimensional solution is given in Eq. 1, where $c$ is the moisture concentration, $c_{o}$ is the saturation moisture concentration, $x$ is the distance from the exposed end, $t$ is the time, $W$ is the width of the specimen $(15.0 \mathrm{~mm})$ and $D$ is the diffusion coefficient. The diffusion coefficient used was $0.451 \mathrm{~mm}^{2} /$ days for the FM73 adhesive [23].

$c(x, t)=c_{o}-\sum_{n=0}^{\infty} \frac{4 c_{o}(-1)^{n}}{(2 n+1) \pi} \cos \left[\frac{(2 n+1) \pi x}{W}\right] e^{\frac{-(2 n+1)^{2} D \pi^{2} t}{W^{2}}}$

This is analogous to heat transfer in a conducting solid and is often analysed using heat transfer elements in a finite element model. A diffusion (transient heat transfer) analysis was performed on a strip of adhesive using three-dimensional elements in Abaqus/Standard. The normalised moisture concentrations (nodal temperatures in a heat transfer analysis) were calculated. The moisture (temperature) distribution obtained from a 3D diffusion (heat transfer) analysis is shown in Fig. 5. Only a half width strip of adhesive was modelled due to symmetry. The width and the thickness of the adhesive strip were $7.5 \mathrm{~mm}$ and $0.1 \mathrm{~mm}$, respectively. The results obtained from 3D diffusion (heat transfer) analysis agreed well with the one-dimensional Fickian diffusion solution. The normalised moisture concentrations were calculated by assuming the ambient concentration equal to 1.0. The data is plotted and shown in Fig. 6. As the moisture concentrations vary over the width of each slice, an average value is calculated for each slice (Slice A, B, C, D and E). It can be seen that the average normalised moisture concentration in Slice $A$ is nearly saturated, being $\approx 0.935$. The average moisture concentration in Slice $E$ is $\approx 0.394$.

\subsection{Finite Element Modelling}

The geometry of the laminate test specimen was modelled in the finite element package ABAQUS. The symmetry of the specimen was exploited using a half model. The top adherend was modelled with a fine mesh as plastic deformations occur at 
the peel front during bending. An initial crack length of $2.0 \mathrm{~mm}$ was modelled in the adhesive bondline. The finite element mesh, the location of the initial crack, the applied load and the boundary conditions in the model are shown in Fig. 7.

The finite element modelling was performed in Abaqus/Standard. Both geometric and material non-linearities were incorporated in the analysis. The yield stress and ultimate strength of 2024-T3 aluminium alloy obtained from tensile tests were 260 $\mathrm{MPa}$ and $450 \mathrm{MPa}$ (at 16\% elongation), respectively. The Young's modulus and Poisson's ratio of the adhesive FM73 were $2000 \mathrm{MPa}$ and 0.4 , respectively [23]. Three-dimensional cohesive zone elements ( $\mathrm{COH} 3 \mathrm{D})$ were used to model the top adhesive layer and continuum elements (C3D4 and C3D8) were employed for the aluminium laminae and the rest of the adhesive layers. A displacement was applied at the loading point and the reaction force (the peel force) was obtained for different crack lengths.

The cohesive zone was modelled using a bilinear traction-separation response. The initial slope of the traction-separation response curves was calculated based on the Young's modulus of the adhesive. The cohesive strength (tripping traction) and the cohesive fracture energy were varied and a parametric study was performed. A pair of cohesive properties (the cohesive strength and the cohesive fracture energy) was obtained that best predicted the experimentally measured $P$ - $a$ response for each moisture level. The results obtained are presented in Section 4.

\section{RESULTS AND DISCUSSIONS}

\subsection{Experimental Results}

The $P$ - $a$ curves were obtained from the miniature peel tests for dry and different wet conditions. Three specimens were tested from each slice (denoted Test 1, 2 and 3) for the $P$-a response. The $P$ - $a$ curves are shown in Fig. 8 along with a regression fit (power fit) for each slice. Further, the $P$-a curves for saturated (Slice A) and dry adhesive conditions are compared in Fig. 9. 
In the peel tests, the bending moment acting at the crack tip plays a key role in generating large local stresses, particularly in a direction perpendicular to the crack length. As the crack length increases in the bondline, the moment arm of the peel force increases (but non-linearly), and thus the peel force required to further propagate the crack decreases. This can be seen in Figs. 8(a-f), where the experimental data obtained for wet (slice $A, B, C, D$ and $E$ ) and dry specimens are shown.

Moisture attacks the adhesive and the interface in bonded joints when exposed to humid environments. The diffusion of water along the interface is often assumed to be faster than in the adhesive material [21]. The interface is more prone in many cases to moisture attack than the adhesive. However, in these properly (with a high quality surface treatment) manufactured bonded joints, the failure is observed to be cohesive and the adhesive degradation under the effect of moisture is the controlling factor on the joint strength. In the peel tests conducted on dry and wet specimens, the failure observed was cohesive in all the peel tests, indicating that the interfacial degradation was not governing the fracture process.

As the moisture diffusion degrades the bondline through different mechanisms, i.e. adhesive plasticization and void formation etc, the peel force required to fracture the bondline decreases with moisture concentration. This was observed in the wet peel tests and is shown in Fig. 9 by comparing the $P$ - $a$ data for wet (slice A) and dry adhesive conditions. For a given crack length, the peel force required to propagate the crack further in the bondline is lowest for Slice A, and highest for the dry condition (see Fig. 9). Using the scanning electron microscopy on the tested specimen, the failure of the bondline for nearly saturated and unsaturated conditions was investigated. The failure was observed to be cohesive in nature in both the conditions (see Fig. 10). 


\subsection{Numerical Results}

\subsubsection{Static analysis of dry joints}

The cohesive zone model discussed in Section 3.4 was employed for the static analysis of the miniature peel test. A displacement was applied at the end of the top adherend and the reaction forces were calculated to initiate and propagate the adhesive damage. The cohesive strength and the cohesive fracture energy values were varied to find a $P$-a curve that was in correlation with the experimentally obtained $P$ - $a$ curves for each moisture levels.

Initially, the cohesive properties, $\left(\sigma_{c}, \Gamma_{c}\right)$, were calibrated for dry adhesive conditions. Any number of CZM parameters can be found that match the P-a curve. However, by also ensuring that the overall predicted adherend deformed shape matches the experimentally measured one it is possible to determine a unique set of cohesive zone model parameters. This process of matching both the P-a curve and the deformed shape was applied and unique values of the cohesive strength $\left(\sigma_{c}\right)$ and the cohesive fracture energy $\left(\Gamma_{c}\right)$ were found to be $65 \mathrm{MPa}$ and $2.0 \mathrm{Nmm}^{-1}$, respectively. The von Mises stress, the equivalent plastic strain and the damage variable (SDEG) distributions are shown in Figs. 11(a), (b) and (c), when the crack length was $2.0 \mathrm{~mm}$ (initial crack). Further, for a crack length of $12.0 \mathrm{~mm}$, the von Mises, the equivalent plastic strain and the damage variable (SDEG) distributions are shown in Figs. 11(d), (e) and (f). The local plastic yielding of the aluminium lamina indicates the contribution of the plastic work to the fracture process.

\subsubsection{Adhesive stress state}

As discussed in Section 3.2, a three-dimensional stress state exists in the adhesive bondline in the peel test. However, the peel stresses dominate the adhesive fracture process. In order to investigate this point, the adhesive stress predicted using the cohesive elements from the dry joint static analysis were used to calculate the 
mode-mixity. The stress state in the bondline under the peel load is shown in Fig. 12 when the crack length was $2.0 \mathrm{~mm}$. The peel stresses (S33) and the shear stresses (S13) were evenly distributed along the width of the adhesive layer. The maximum peel (S33) and shear stress (S13) were $65 \mathrm{MPa}$ (the cohesive strength) and $34.8 \mathrm{MPa}$, respectively. Moreover, as the bending of the adherend was accompanied by the anticlastic curvature, shear stresses (S23) along the adhesive width were induced. The magnitude of these shear stresses depends on the width of the test specimen. In the miniature peel test (the width of the specimen was $1.0 \mathrm{~mm}$ ), the maximum shear stress was $7 \mathrm{MPa}$ at the free edge and vanished in the middle of the adhesive layer.

Further, the stress state in the bondline under the peel load is shown in Fig. 13 when the crack length was $12.0 \mathrm{~mm}$. The maximum peel (S33) and shear stress (S13) were $65 \mathrm{MPa}$ and $37.6 \mathrm{MPa}$, respectively. The maximum shear stress (S23) was 9.2 MPa at the free edge and vanished in the middle of the adhesive layer. The mode-mixity was calculated based on the peel and shear stresses. The variation of the phase angle for mode-I/II, $\varphi_{I, I I}=\tan ^{-1}\left(\tau_{13} / \sigma_{33}\right)$, and for mode-I/III, $\varphi_{I, I I}=\tan ^{-1}\left(\tau_{23} / \sigma_{33}\right)$, with crack length is schematically shown in Fig. 14 . The range of phase angles, being $\left(27^{\circ}-30^{\circ}\right)$ for mode-I/II and $\left(6^{\circ}-8^{\circ}\right)$ for mode-I/III, when the crack length increased from 2.0 $\mathrm{mm}$ to $12.0 \mathrm{~mm}$, indicate the fact that the peel stresses dominated the fracture process in the miniature cantilever peel test.

\subsubsection{Effect of plastic deformations}

As the aluminium laminae in the tested specimens are very thin $(1.3 \mathrm{~mm}), \mathrm{a}$ considerable amount of adherend plasticity (permanent deformation) was observed in the miniature peel tests. In this regard, the aluminium adherend was modelled using a non-linear material behaviour and the plastic energy dissipation during the fracture process was estimated. The adherend deflections obtained from both the miniature peel test and the finite element model were compared and found to be in good agreement. It is shown in Fig. 15 for dry adhesive condition for a crack length of nearly $12 \mathrm{~mm}$ - a vertical deflection of approximately $3 \mathrm{~mm}$ was seen in both the 
cases. Moreover, the total energy contributions were estimated from the finite element analysis during the fracture process. The variation of the total elastic strain energy (recoverable), the total plastic and fracture energies (irrecoverable) versus adhesive crack length is shown in Fig. 16. The variation of the total elastic and fracture energies varied linearly with adhesive crack length (see Fig. 16(a) and (b)), whereas the total plastic energy was varied non-linearly (see Fig. 16(c)). Further, it can be seen that the energy absorbed in plastic deformation is very significant and must be incorporated in any analysis that is seeking to determine adhesive fracture energies.

\subsubsection{Moisture diffusion}

As discussed in Section 3.3, the moisture diffusion in the adhesive was calculated using a one-dimensional Fickian solution and a three-dimensional finite element analysis. It was found that both the solutions correlate well with each other. Normalised moisture concentrations were calculated for the finite element analysis by assuming the ambient concentration as 1.0 .

Moreover, as the moisture concentrations vary along the width of each slice in an unsaturated condition, an average of the normalised moisture concentration was calculated for each slice after 360 days of exposure to de-ionised water. The average normalised moisture concentrations for each slice is taken from Fig. 6 and presented in Table 1.

\subsubsection{Moisture-dependent cohesive properties}

The $P$ - $a$ curves obtained from the miniature peel tests for each slice were used to calibrate the cohesive properties. As the moisture attacks the adhesive and degrades the mechanical properties, the cohesive strength, the cohesive fracture energy and the Young's modulus values were numerically degraded in the finite element model. It was assumed for simplicity that all the three material variables will be degraded equally in percentage. 
Using this degradation strategy and the initial (dry) values (65 MPa, $2.0 \mathrm{Nmm}^{-1}$ and $2000 \mathrm{MPa}$ for the cohesive strength, the cohesive fracture energy and the Young's modulus, respectively), a parametric study was performed by reducing the three variables to calibrate the $P$-a curves with the experimentally obtained $P$ - $a$ responses for each slice (moisture level). The calibrated $P$ - $a$ curves for wet (Slice A, B, C, D and E) and dry adhesive condition are shown in Fig. 17. The calibrated cohesive properties and the Young's modulus values for each slice (moisture level) are given in Table 2. It was found that the fracture energy was reduced by approximately $16 \%$ from the initial (dry) value when the adhesive was nearly saturated (in Slice A). The comparison of the predicted $P$ - $a$ curves for nearly saturated (Slice A) and dry adhesive conditions is shown in Fig. 18.

\section{CONCLUSIONS}

A combined experimental-numerical approach was developed to determine the moisture-dependent cohesive zone properties for mode-I dominated fracture in adhesively bonded laminates. Adhesively bonded aluminium alloy laminate Al 2024T3/FM73 was immersed in de-ionised water at $50^{\circ} \mathrm{C}$. The current methodology was employed to characterise the moisture-dependent cohesive properties for the Al 2024-T3/FM73 adhesive system. The following conclusions were drawn:

(a) The miniature cantilever peel test employed can be used to obtain the peel force versus crack length responses for different moisture concentration levels.

(b) Using the cohesive-zone finite element model of the miniature peel test, the cohesive properties of the bondline for different moisture levels can be calibrated against the experimental data.

(c) It was found that the cohesive fracture energy of the adhesive FM73 used in the laminate was degraded by nearly $16 \%$ when it was exposed to de-ionised water at $50^{\circ} \mathrm{C}$ to near saturation conditions. 
(d) This miniature specimen strategy can easily be used on different aged and unsaturated adhesively bonded joint systems exposed to hostile environmental conditions to determine degraded material properties for subsequent use in environmental damage modelling of more complex adhesively bonded structures.

\section{ACKNOWLEDGEMENTS}

The authors acknowledge TSB, Airbus Operations Ltd (UK), BAe Systems and Imperial College for their support. 


\section{REFERENCES}

[1] Higgins A. Adhesive bonding of aircraft structures. Int J Adhes Adhes 2000; 20: 367-76.

[2] Taljsten B. The importance of bonding-a historic overview and future possibilities. Adv Struct Eng 2006; 9-6: 721-36.

[3] Dilger K. Automobiles. In: Adams RD, editor. Adhesive bonding: Science, technology and applications, Cambridge: Woodhead publishing Itd; 2005, p. 357-385.

[4] Hart-Smith L. Aerospace. In: Adams RD, editor. Adhesive bonding: Science, technology and applications, Cambridge: Woodhead publishing Itd; 2005, p. 489-527.

[5] Adams RD, Comyn J, Wake WC. Structural adhesives joints in engineering. London: Chapman \& Hall; 1997.

[6] Adams RD, Cowap JW, Farquharson G, Margary GM, Vaughn D. The relative merits of the Boeing wedge test and the double cantilever beam test for assessing the durability of adhesively bonded joints, with particular reference to the use of fracture mechanics. Int J Adhes Adhes 2009; 29: 609-20.

[7] Messler RW. Joining of advanced material. Boston: Butterworth-Heinemann; 1993.

[8] Crocombe AD, Hua YX, Loh WK, Wahab MA, Ashcroft IA. Predicting the residual strength of environmentally degraded adhesive lap joints. Int J Adhes Adhes 2006; 26: 325-36.

[9] Hua YX, Crocombe AD, Wahab MA, Ashcroft IA. Continuum damage modelling of environmental degradation in joints bonded with E32 epoxy adhesive. J Adhes Sci Technol 2007; 21: 179-95.

[10] Loh WK, Crocombe AD, Wahad MA, Ashcroft IA. Modelling interfacial degradation using interfacial rupture elements. J Adhes 2003; 79: 1135-60.

[11] de Borst R. Numerical aspects of cohesive-zone elements. Eng Fract Mech 2003; 70: 1743-57.

[12] Barenblatt Gl. The mathematical theory of equilibrium cracks in brittle fracture. Adv Appl Mech 1962; 7: 55-129. 
[13] Dugdale DS. Yielding of steel sheets containing slits. J Mech Phys Solids 1960; 8: 100-8.

[14] Hillerborg A, Modeer M, Petersson PE. Analysis of crack formation and crack growth in concrete by means of fracture mechanics and finite elements. Cem Con Res 1976; 6: 773-82.

[15] Peter AG, Anthony MW. The influence of adhesive constitutive parameters in cohesive zone finite element models of adhesively bonded joints. Int J Solids Struct 2009; 46: 2201-15.

[16] Liljedahl CDM, Crocombe AD, Wahab MA, Ashcroft IA. Damage modelling of adhesively bonded joints. Int J Fract 2006; 141-1: 147-61.

[17] Sørensen BF, Kirkegaard P. Determination of mixed mode cohesive laws. Eng Fract Mech 2006; 73-17: 2642-61.

[18] Loh WK, Crocombe AD, Wahab MA, Ashcroft IA. Environmental degradation of bonded joint interfacial fracture energy. Eng Fract Mech 2002; 69: 211328.

[19] Liljedahl CA, Crocombe AD, Wahab MA, Ashcroft IA. Modelling the environmental degradation of the interface in adhesively bonded joints using a cohesive zone approach. J Adhes 2006; 82-11: 1061-89.

[20] Anderson GP, Bennett SJ, DeVries KL. Analysis and testing of adhesive bonds. New York: Academic Press; 1977.

[21] Sargent JP, Wilson Q. Prediction of "Zed" section stringer pull-off loads. Int J Adhes Adhes 2003; 23: 189-98.

[22] Lin YY, Hui CY, Wang YC. Modelling the failure of an adhesive layer in a peel test. J Polym Sci, Part B: Polym Phy 2002; 40- 19: 2277-91.

[23] Liljedahl CDM, Crocombe AD, Wahab MA, Ashcroft IA. Modelling the environmental degradation of adhesively bonded aluminium and composite joints using a CZM approach. Int J Adhes Adhes 2007; 27-6: 505-18.

[24] Volokh KY (2004). Comparison between cohesive zone models. Comm Num Meth Eng 2004; 20: 845-56. 
Figures

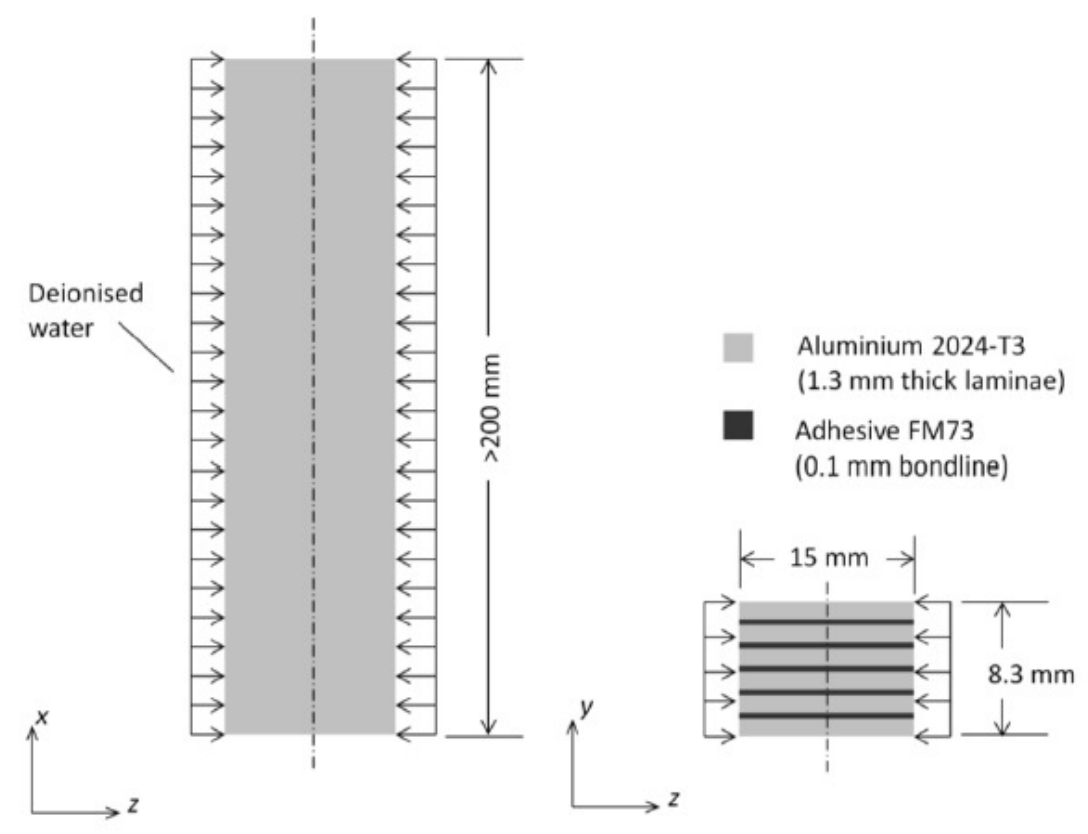

FIGURE 1: The adhesively bonded aluminium alloy laminate exposed to de-ionised water at $50^{\circ} \mathrm{C}$.

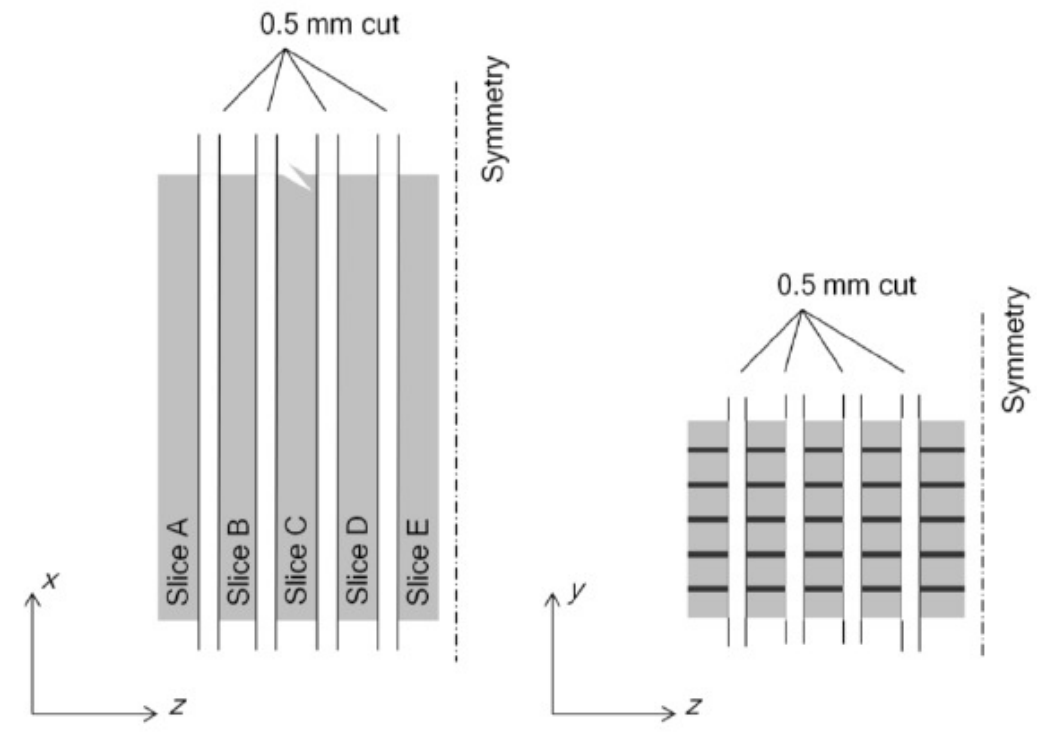

FIGURE 2: The location of the thin slices (5 slices) cut from the adhesively bonded laminate. 


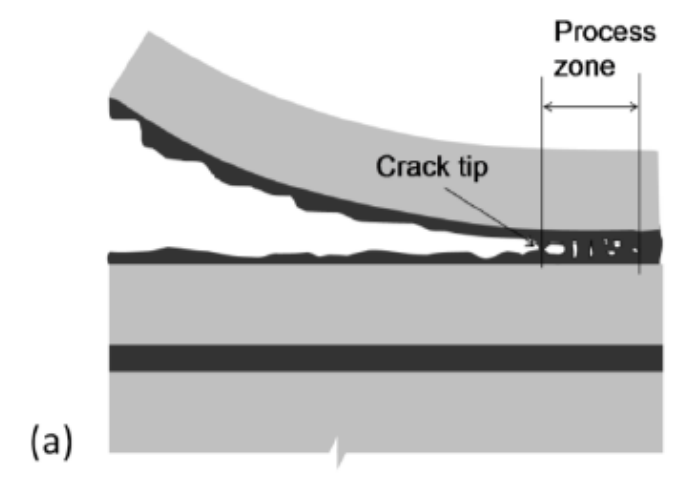

(b)

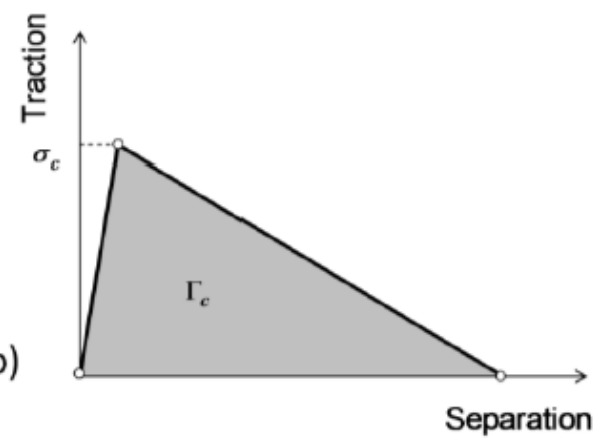

FIGURE 3: The cohesive zone model: (a) the process zone in adhesively bonded metal laminate and (b) a bilinear traction-separation response

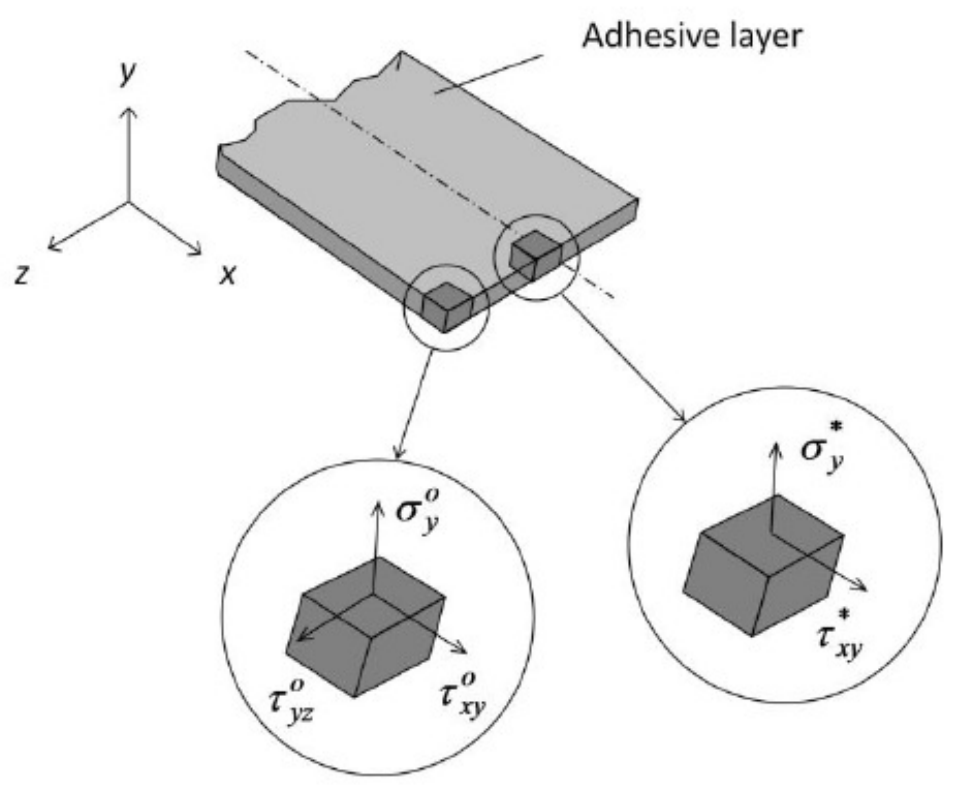

FIGURE 4: The stress state in the adhesive bondline in the cantilever peel test 


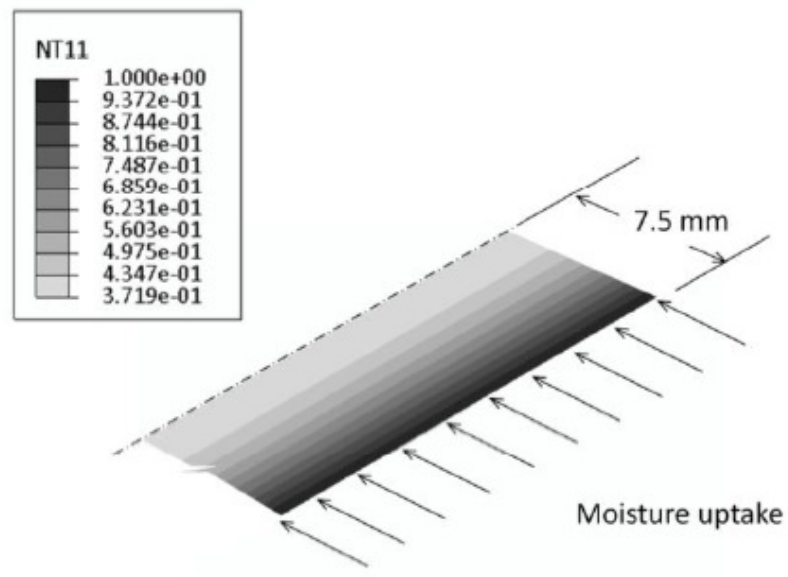

FIGURE 5: Moisture (temperature) distribution in the adhesive layer from a $3 D$ diffusion (heat transfer) analysis

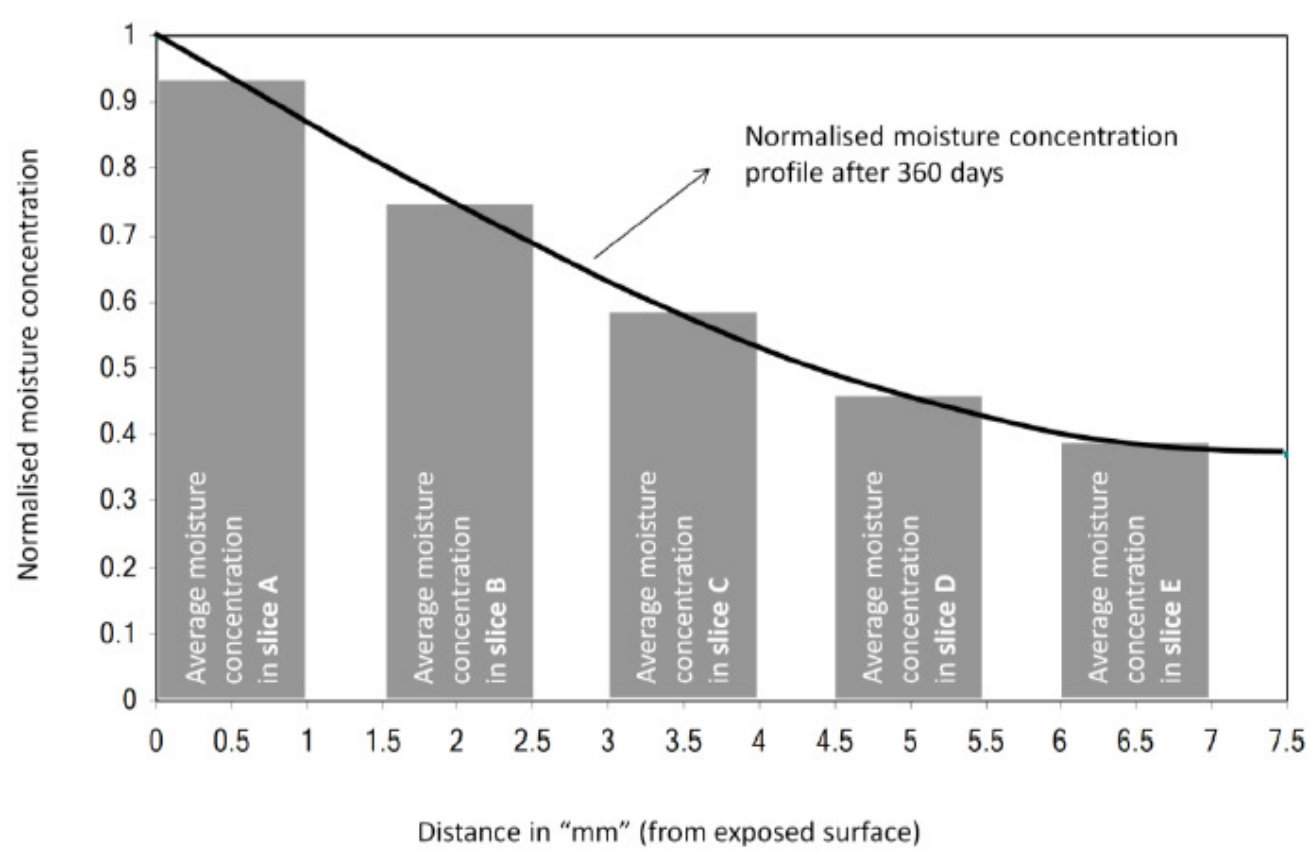

FIGURE 6: The normalised moisture concentration profile and the average moisture concentrations in each slice in the adhesive bondline after an exposure period of 360 days. 


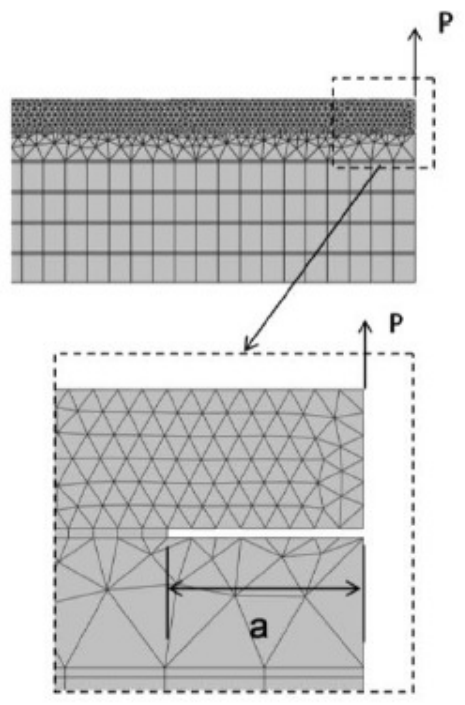

(a) (b)

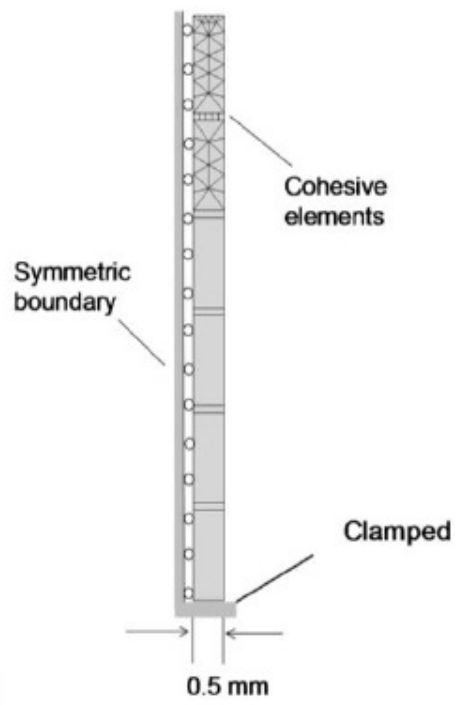

FIGURE 7: The finite element modelling: (a) the initial crack $a$ in the adhesive and (b) the symmetric boundary condition. 


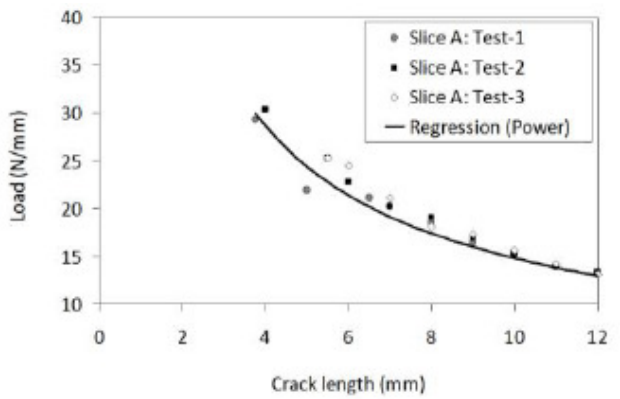

(a) Load-crack length response for slice $A$

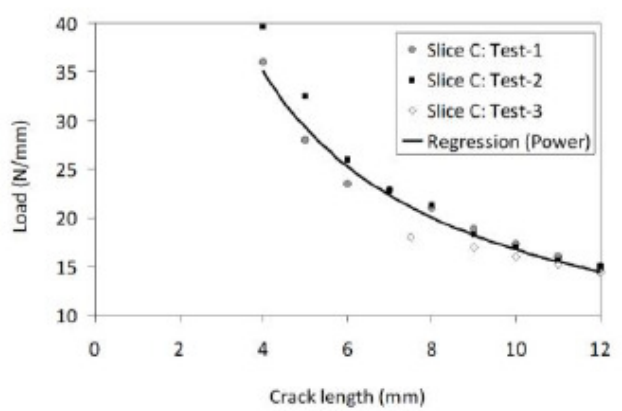

(c) Load-crack length response for slice $C$

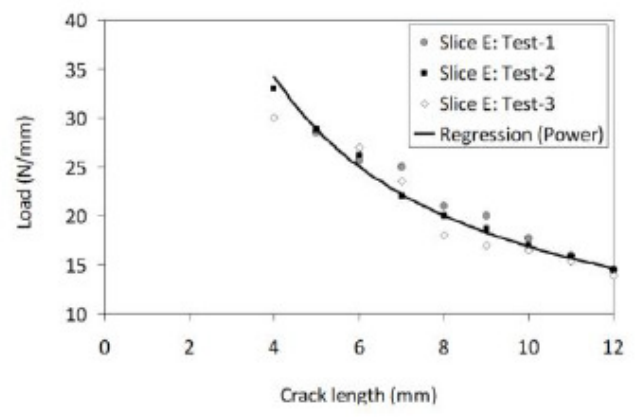

(e) Load-crack length response for slice $E$

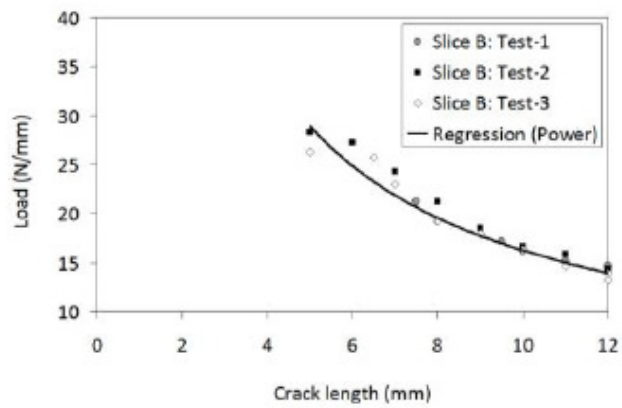

(b) Load-crack length response for slice B

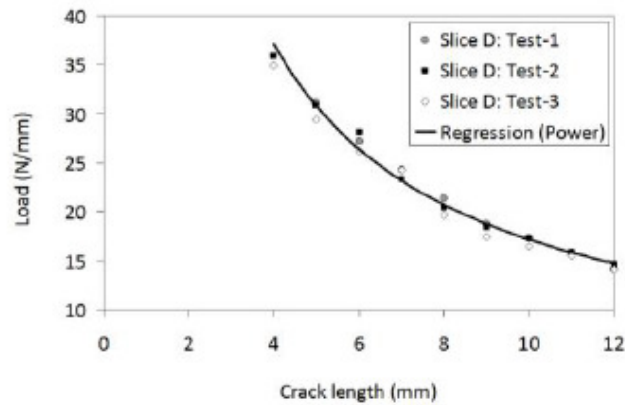

(d) Load-crack length response for slice D

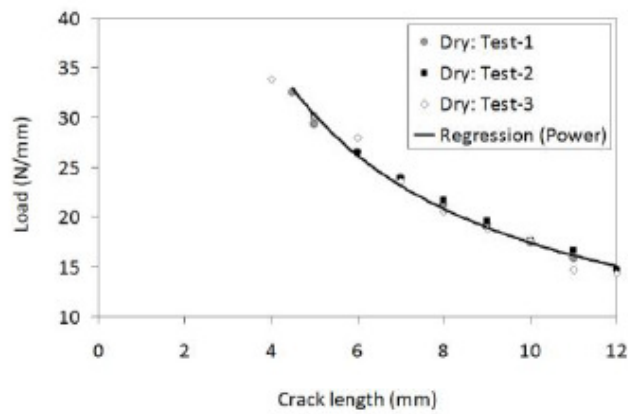

(f) Load-crack length response for dry

FIGURE 8: The load versus crack length data obtained from the peel tests on wet (after 360 days) and dry specimen 


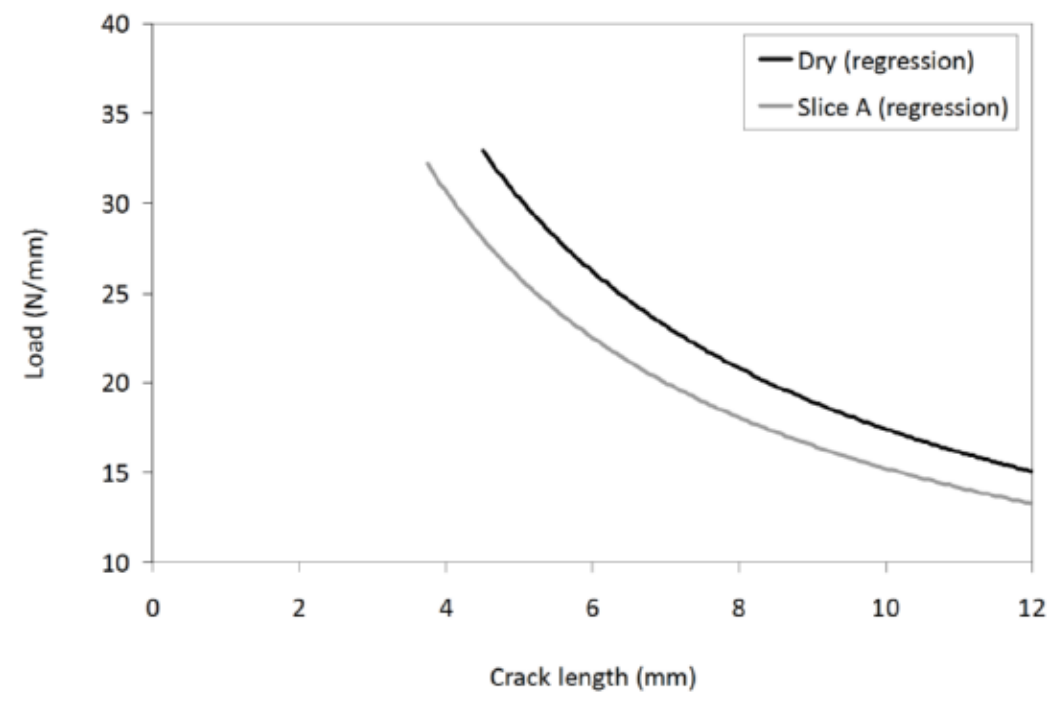

FIGURE 9: Comparison of the P-a data (regression curves) for wet and dry conditions

(a)

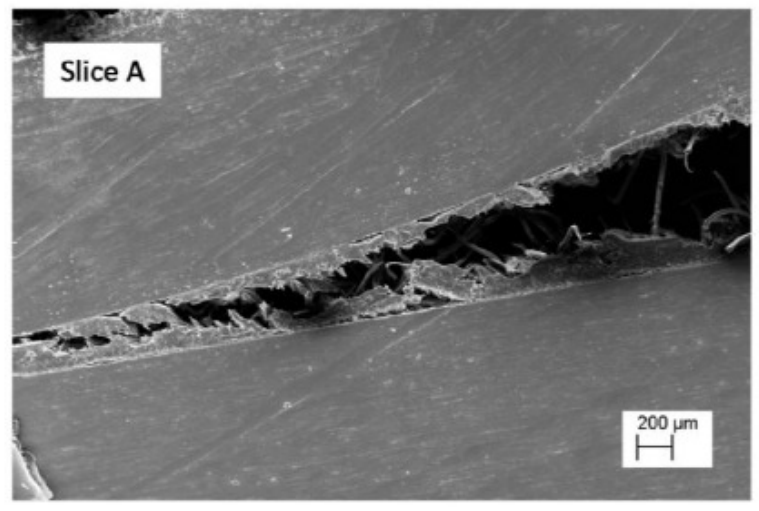

(b)

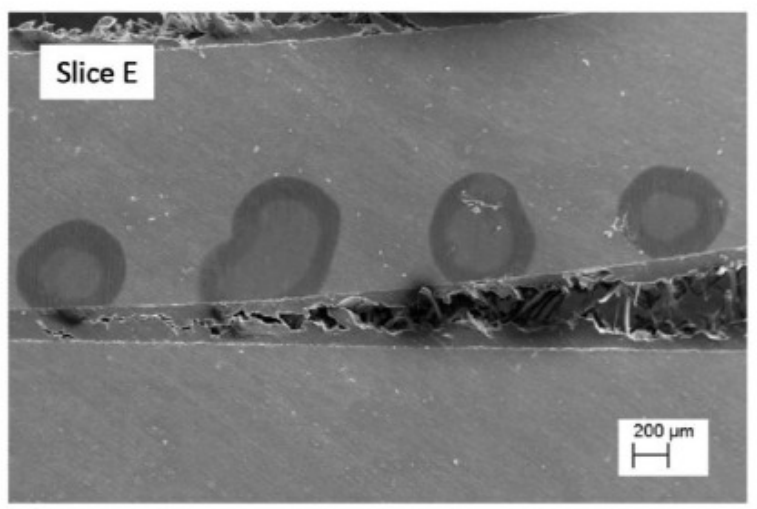

FIGURE 10: The failure of the adhesive bondline: (a) the nearly saturated adhesive bondline (Slice A) and (b) the unsaturated adhesive bondline (Slice E) 

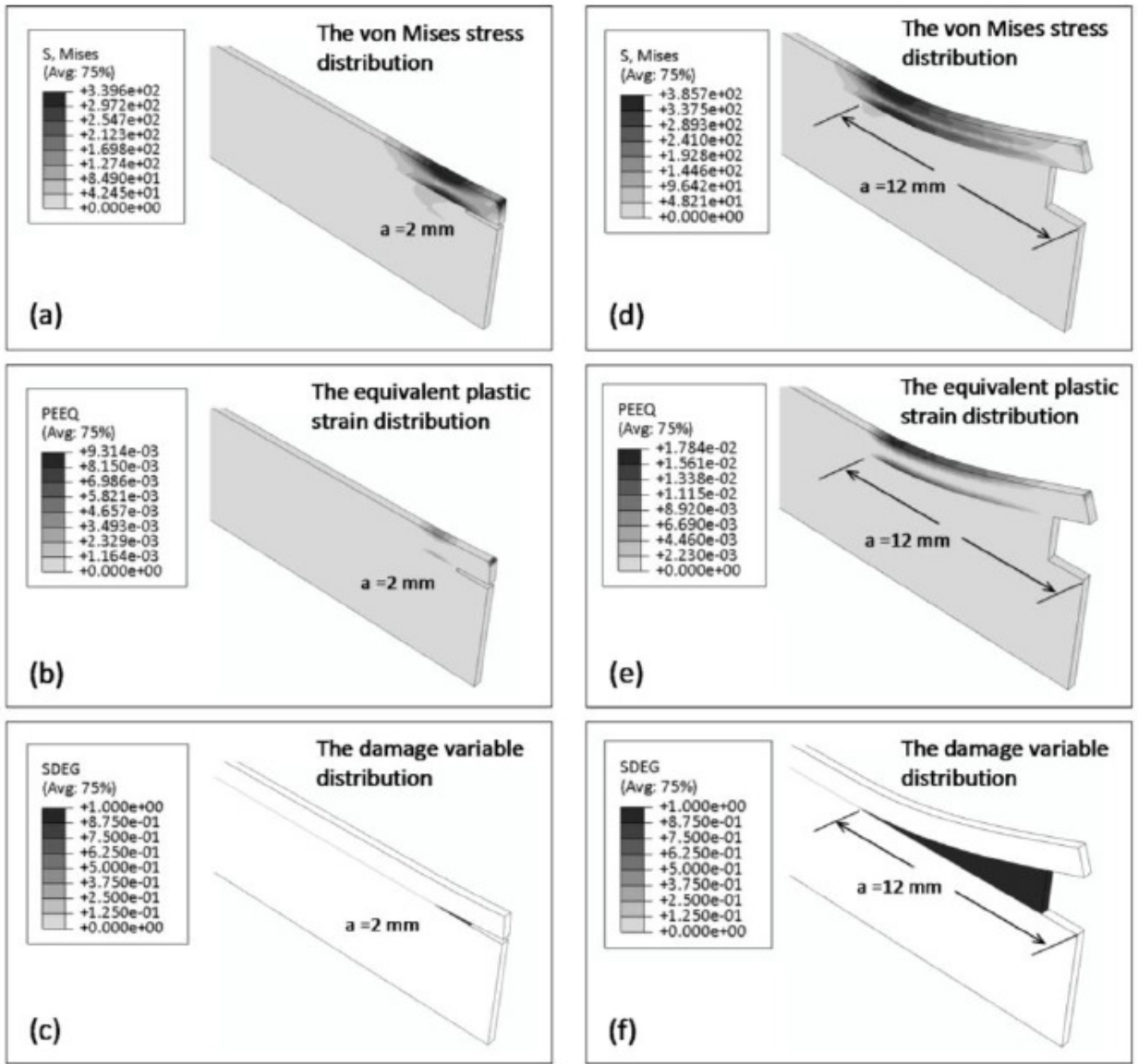

FIGURE 11: The von Mises stress, the equivalent plastic strain and the damage distributions predicted for the dry adhesive condition for $2 \mathrm{~mm}$ and $12 \mathrm{~mm}$ crack lengths 

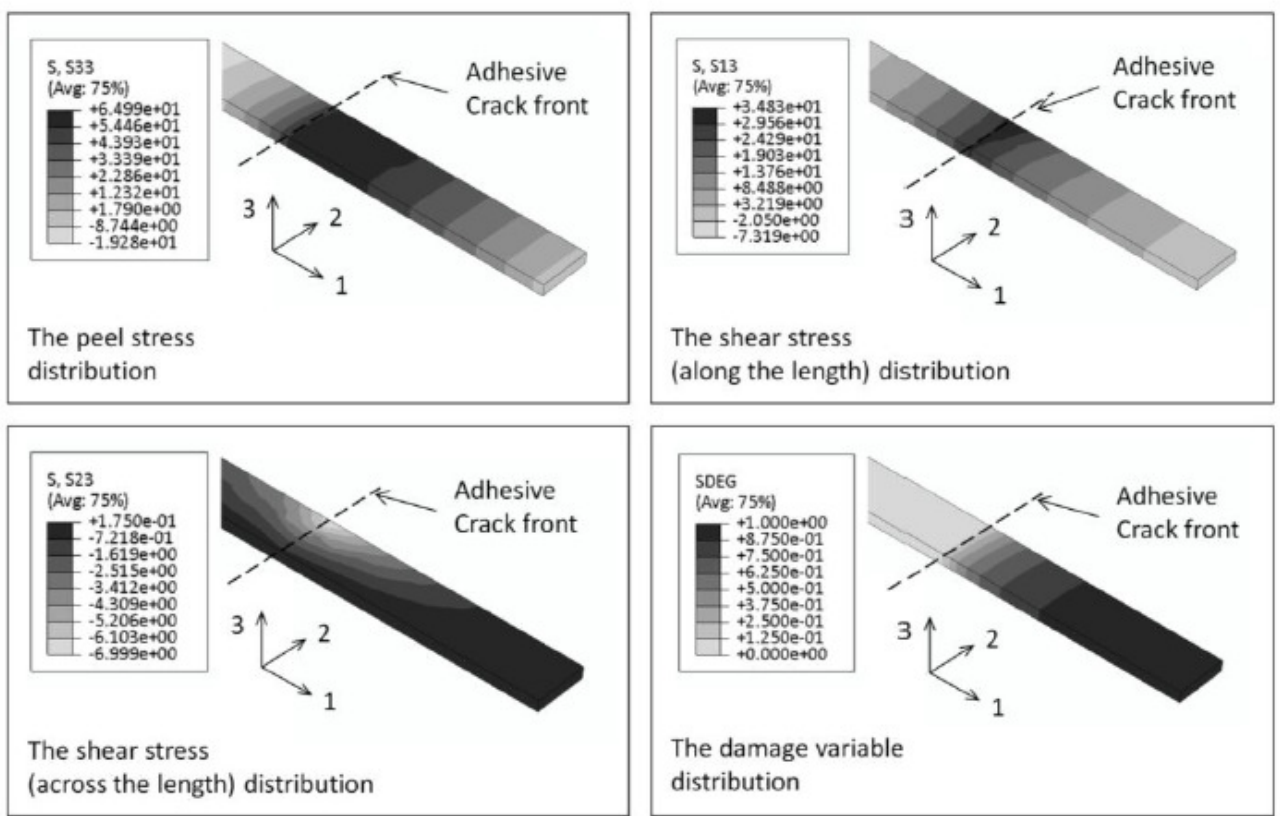

FIGURE 12: The stress and damage distributions in the adhesive bondline for a crack length of $2.0 \mathrm{~mm}$ for dry condition: (a) the peel stress (S33), (b) the shear stress (S13), (c) the shear stress (S23), and (d) the damage variable (SDEG) 

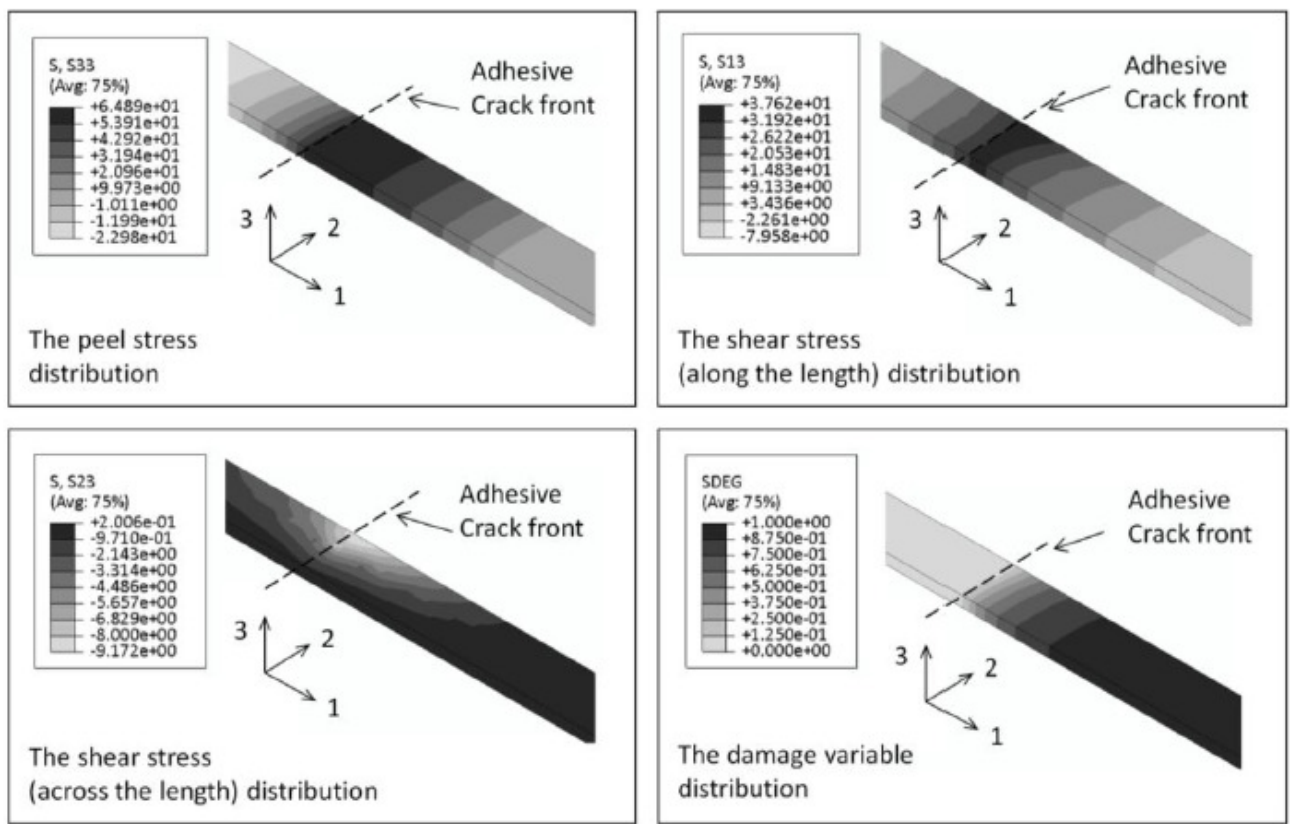

FIGURE 13: The stress and damage distributions in the adhesive bondline for a crack length of $12.0 \mathrm{~mm}$ for dry condition: (a) the peel stress (S33), (b) the shear stress (S13), (c) the shear stress (S23), and (d) the damage variable (SDEG)

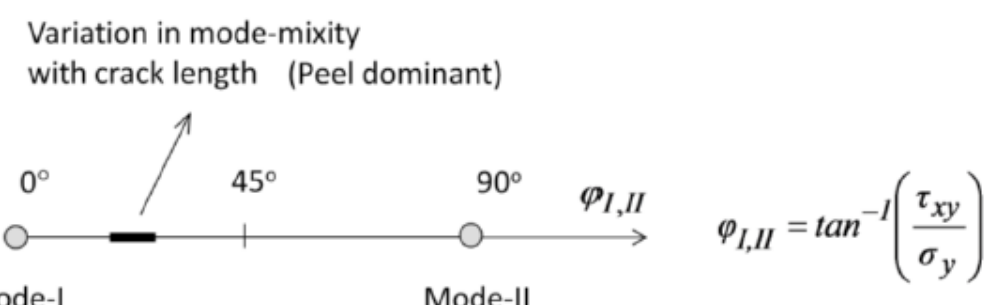

(a) Mode-I

Mode-II

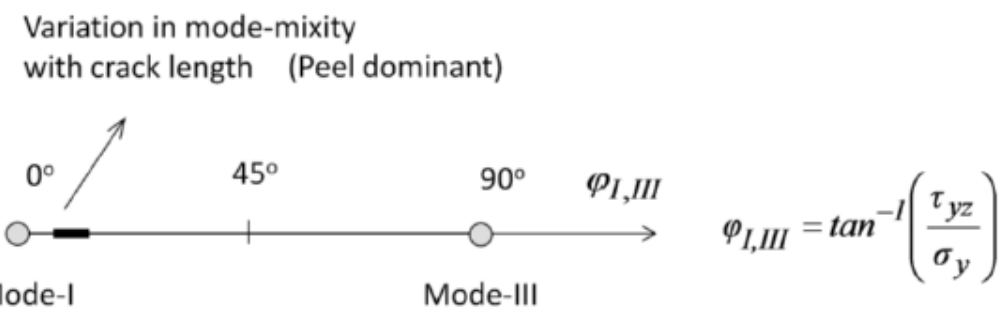

FIGURE 14: The variation of mode-mixity (mode-I/II and mode-I/III) with the adhesive crack length in the miniature peel test 


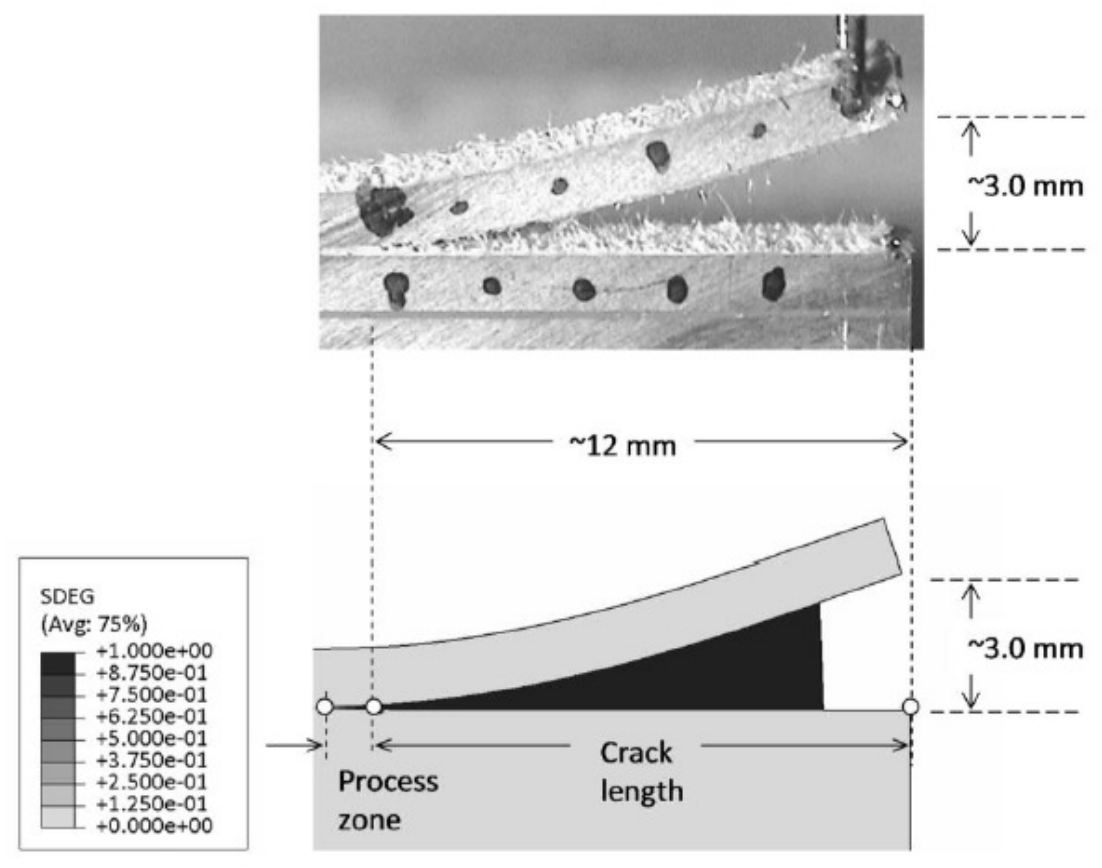

FIGURE 15: The comparison of the adherend deflections from the miniature peel test and the finite element model for a crack length of $12 \mathrm{~mm}$ in dry condition 
(a)

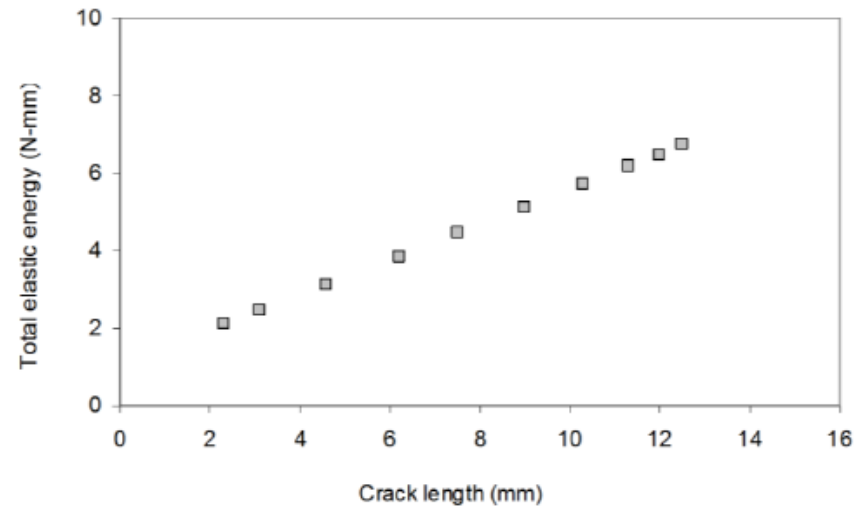

(b)

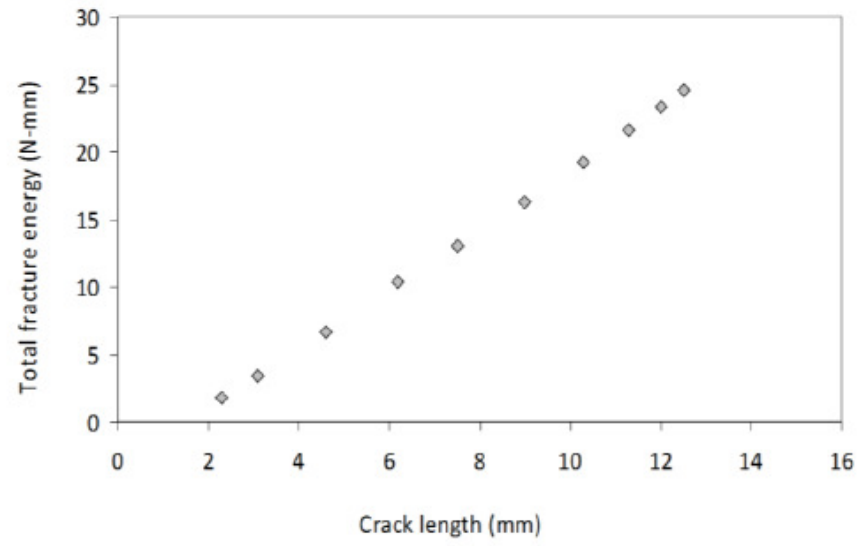

(c)

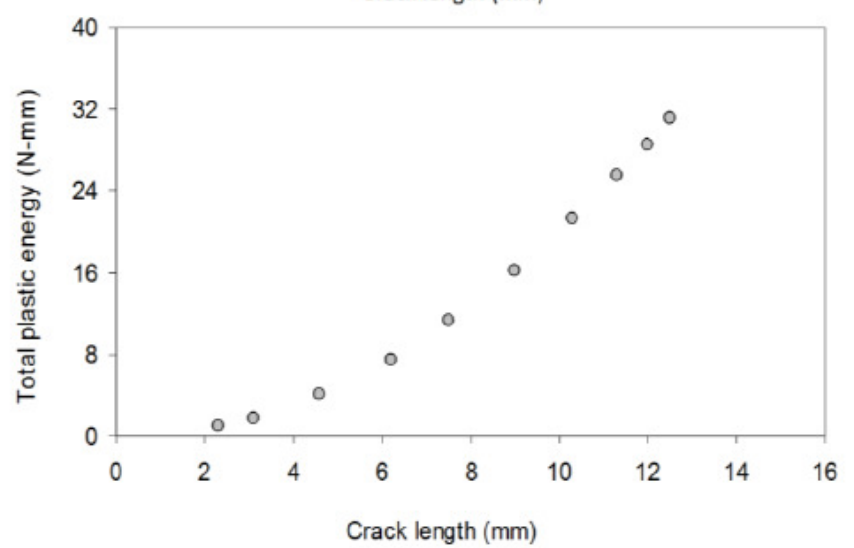

FIGURE 16: The predicted variation of the total elastic, plastic and fracture energies with adhesive crack length. 


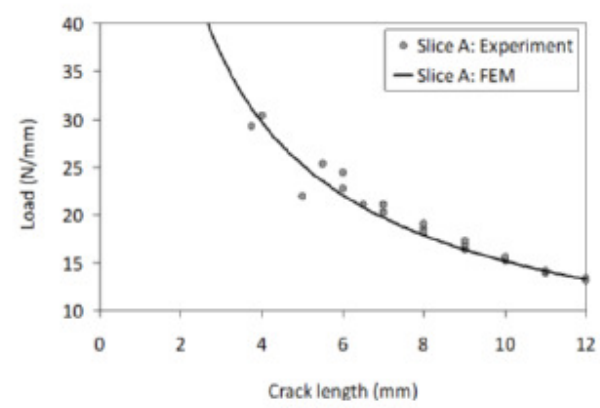

(a) Load-crack length response for slice A

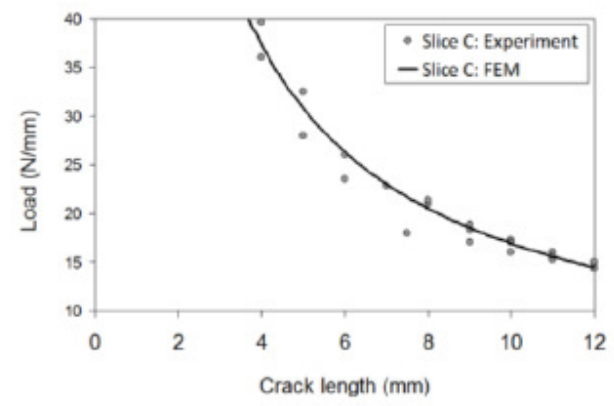

(c) Load-crack length response for slice C

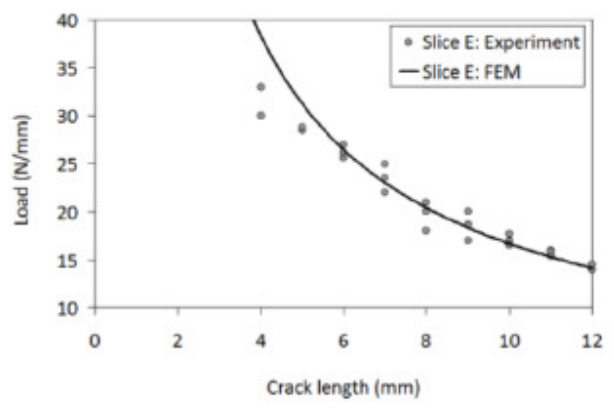

(e) Load-crack length response for slice $\mathrm{E}$

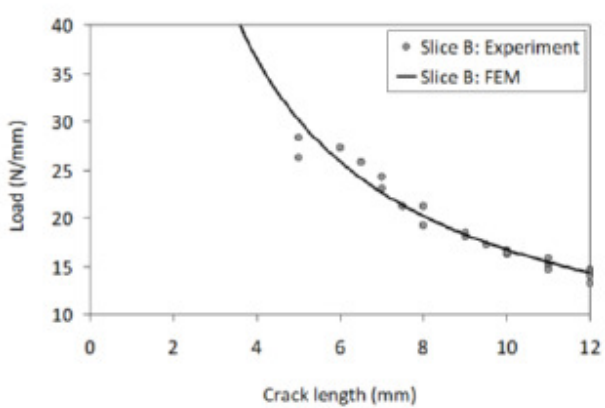

(b) Load-crack length response for slice B

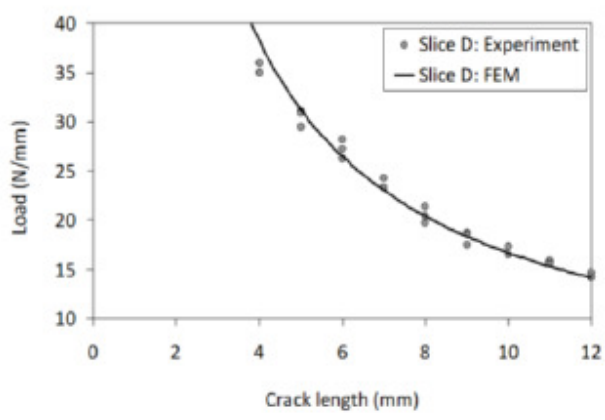

(d) Load-crack length response for slice D

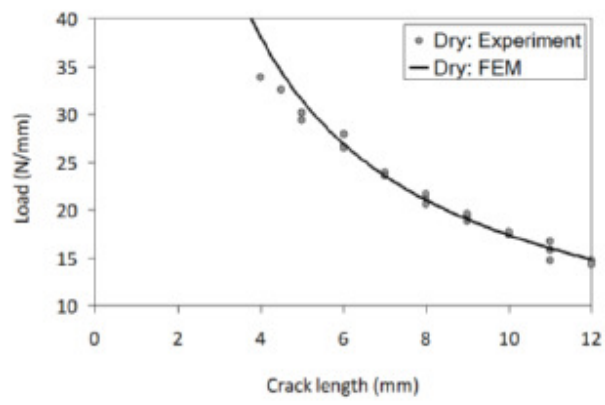

(f) Load-crack length response for dry

FIGURE 17: Comparison of the predicted P-a curves with the experimental data 


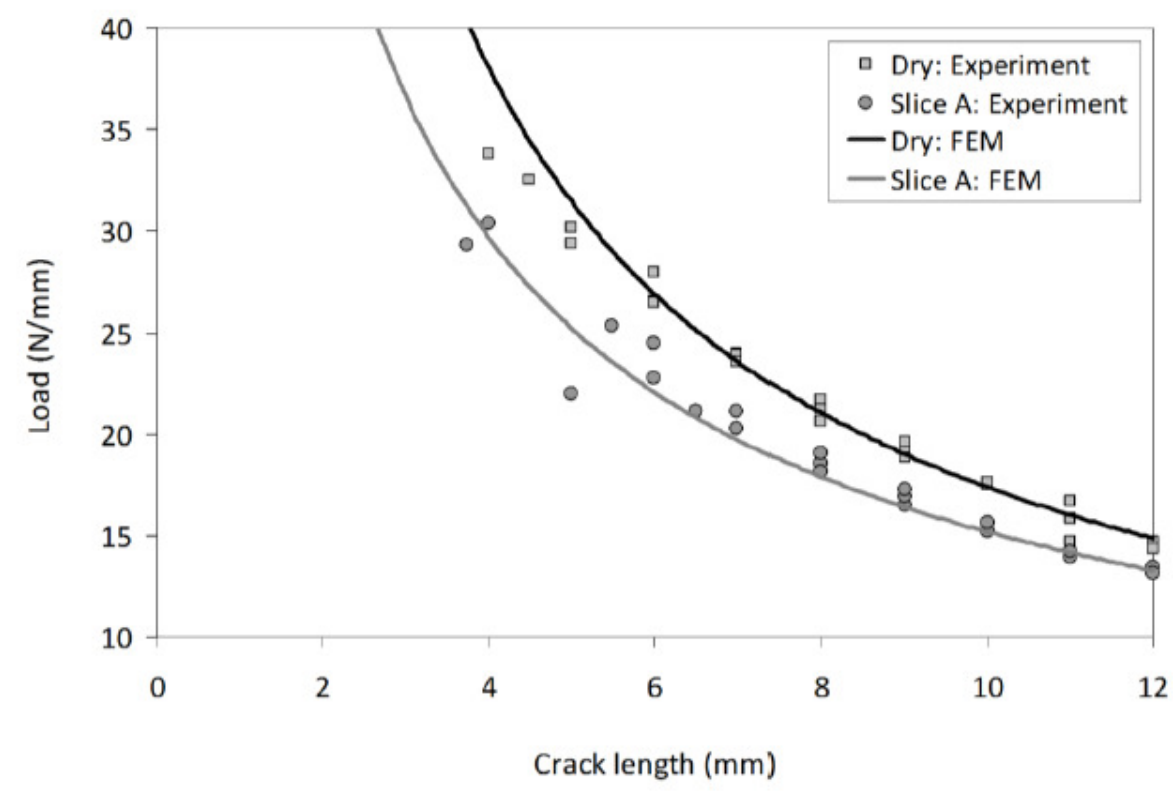

FIGURE 18: Comparison of the predicted P-a curves for wet (slice $A, B, C, D$ and E) and dry adhesive conditions 